to be completely decomposed. Whether in the presence of such large amounts of lead sulphate $5 \mathrm{cc}$. of $4^{8}$ per cent. hydrofluoric acid are sufficient to transform all the accompanying stannic and antimonious sul-

\begin{tabular}{|c|c|c|}
\hline & $\begin{array}{l}\text { I. } \\
\text { Percent. }\end{array}$ & $\begin{array}{l}2 . \\
\text { Per cent. }\end{array}$ \\
\hline Lead $\ldots \ldots \ldots \ldots \ldots \ldots \ldots$ & trace & $47 \cdot 4 \mathrm{I}$ \\
\hline Antimony. . . . . . . . . . . & 38.30 & ro. 46 \\
\hline $\operatorname{Tin} \ldots \ldots \ldots \ldots \ldots \ldots \ldots$ & $6 r \cdot 30$ & 40.40 \\
\hline Copper. ................. & O.I2 & Ү. 82 \\
\hline Arsenic. . . . . . . . . . . . . . . & $\ldots$ & $\ldots$ \\
\hline & 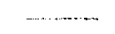 & . \\
\hline & $99.7^{2}$ & 100.09 \\
\hline
\end{tabular}

phates into fluorides remains to be seen. Any antimonic acid formed by the nitric acid can be reduced to antimonious oxide by sprinkling some sulphur over the concentrated sulphuric acid, after all the nitric acid has been expelled, and again heating to strong fuming for about fifteen minutes. The reduction is of course effected by the sulphur dioxide formed.

PRINCETON. N. J.

[CONTRIBUTION FROM THE JOHN HARRISON LABORATORY OF CHEMISTRY.]

\title{
THE DETERMINATION OF INDIUM WITH THE USE OF A MERCURY CATHODE.
}

BY I.LLY G. KOLLOCK AND EDGAR 1i. SMIIH

Received July 23, 1910.

Thiel ${ }^{1}$ recommends the use of a silver-plated platinum cathode for the deposition of metallic indium. Dennis and Greer $^{2}$ found that this metal may be readily precipitated on a rotating platinum dish cathode from solutions of its chloride or nitrate in the presence of pyridine, hydroxylamine or formic acid.

The purpose of the present communication is to offer the results obtained in the electro-analytical behavior of indium toward a mercury cathode.

A solution of indium sulphate (IO.I 5 grams of metal in $500 \mathrm{cc}$.) containing a small amount of free acid was the electrolyte. A mercury cup of the usual form was employed. ${ }^{3}$ The method followed and precautions taken were identical with those described in the determination of other metals with the same apparatus.

With a total dilution of 10 cc., a current varying from 2 to 4 amperes, an e. m. f. of 7.5 to 6.5 volts, and an anode rotating $75^{\circ}$ times per minute, the following results were obtained:

0.1013, 0.1008, 0.1010, 0.1013, 0.10II, 0.1010, 0.10I1, 0.10II gram

$1 Z$. anorg. Chem., 39, I19.

${ }^{2}$ Ber., 37, 75; This Journal, 26, 438.

'Smith's Electro-analysis, p. 58, 4th Ed. 
The time for actual electrolysis was 5 minutes. Doubling the quantity of solution also gave concordant results after i 8 minutes' action of the current:

$$
0.2021,0.2021,0.2020,0.2021,0.2019,0.2021 \text { gram }
$$

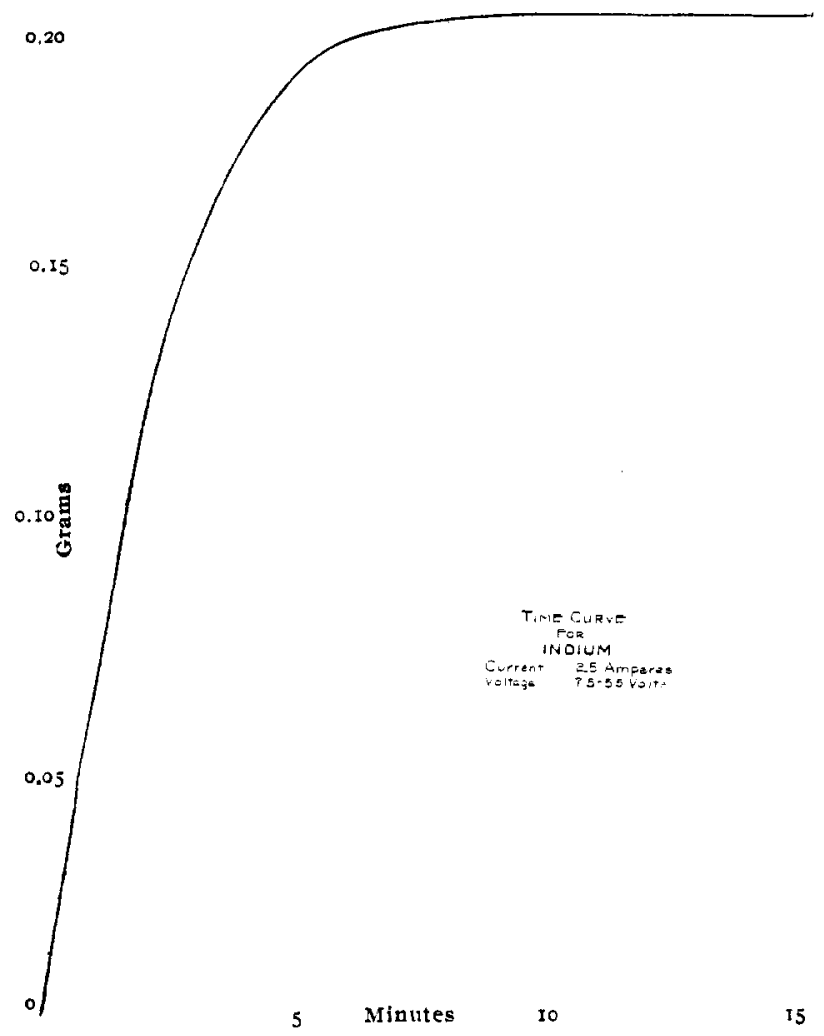

The accompanying time curve was made under the following conditions:

Vol. of sol...................... ro $\mathrm{cc}$.

Indium present................... 0.2020 gram

Current strength.................. 2.5 amperes

E. m. f....................... $7 \cdot 5-5 \cdot 5$ volts

R. p. m. of anode.................. 750

Dr. John Frazer, of this Laboratory, conducted a number of determinations of indium, using a platinum cathode with a platinum spiral anode, rotating 250 to 400 times per minute. In the presence of o.I cc. of concentrated sulphuric acid and a few drops of gelatin a beautiful, adherent deposit of indium was obtained with a current of $N . D_{\text {Ioo }}=3$ amperes 
and a pressure of from 4.5 to 5 volts. The precipitation was complete in twenty-five minutes.

A potassium cyanide electrolyte proved satisfactory; while in the presence of 2 grams of sodium acetate, $0.2 \mathrm{cc}$. of normal acetic acid and several drops of gelatin, a current of 5.6 amperes and 4 volts deposited the metal in a beautiful, adherent form in forty minutes. The temperature of the electrolyte was maintained at $60^{\circ}$. The most satisfactory deposits of this metal were obtained, however, from an electrolyte containing from 0.75 gram to 1.5 grams of Rochelle salt. They were brilliant in appearance and perfectly adherent. They resembled such coatings as are produced by fresh aluminium paint. They were preserved without alteration or loss of luster.

university of Pennsylvania.

[CONTRIbUtions From the Havemeyer Laboratories, Columbia University, No. 180.$]$

\section{A NEW VOLUMETRIC METHOD FOR THE DETERMINATION OF MANGANESE.}

By F. J. MEtzger AND Robert F. MCCrackan.

Received July 20, 1910.

In a previous number of THIS JoURNAL ${ }^{1}$ mention was made of the fact that manganese, in sulphuric acid solution, was oxidized to the quadrivalent form by means of sodium bismuthate, and that the manganese remained in solution in this state of oxidation. It is the purpose of this paper to describe a method based on the above principle whereby the manganese may be accurately determined.

Solutions Used.-A o. I $N$ potassium permanganate solution, and a solution of ferrous sulphate of about equivalent strength. A solution of manganous sulphate was prepared and carefully standardized gravimetrically by weighing as pyrophosphate.

Method.-Place $50 \mathrm{cc}$. of the standard manganese solution in a $300 \mathrm{cc}$. Erlenmeyer flask, add Io-I 5 cc. of concentrated sulphuric acid and allow to cool. Add I-2 grams of finely powdered sodium bismuthate in such a way that none of the powder sticks to the sides of the flask. Place the flask in a beaker of water so that the level of the solution is several inches below the level of the water in the beaker. Heat slowly to boiling and boil till the precipitate of basic bismuth compound settles well and has a granular appearance (about 20 minutes' boiling is usually necessary). Remove the flask and cool under running water, add a known excess of ferrous sulphate solution, dilute to about $200 \mathrm{cc}$. and titrate back with standard permanganate solution.

1 Metzger and Heidelberger, THIS JournaL, 32, 643. 